\title{
Electro-Physical Properties of Super-Thin Basalt Fiber Chemically Modified by Hydrochloric or Sulphuric Acid
}

\author{
Sergey K. Nikoghosyan ${ }^{1}$, Aram A. Sahakyan ${ }^{1}$, Vasak B. Gavalyan ${ }^{1}$, Vachagan V. Harutyunyan ${ }^{1}$, \\ Aghasi S. Hovanisyan ${ }^{1}$, Hrant N. Yeritsyan ${ }^{1^{*}}$, Vovik A. Atoyan ${ }^{2}$, Konstantin I. Puskulyan $^{2}$, \\ Mark Gerchikov ${ }^{3}$, Narek V. Hakobyan ${ }^{4}$, Artur V. Hovhannisyan ${ }^{5}$ \\ ${ }^{1}$ A.I. Alikhanyan National Science Laboratory, 2 Alikhanyan Brothers Str., Yerevan, Armenia \\ ${ }^{2}$ Armenian Nuclear Power Plant, Metcamor Region, Armenia \\ ${ }^{3}$ Nuclear Safety Solutions Limited, Toronto, Canada \\ ${ }^{4}$ Physics Department, Yerevan State University, Yerevan, Armenia \\ ${ }^{5}$ Ra State Nuclear Safety Regulatory Committee by the Government, Yerevan, Armenia \\ E-mail:"Grant@yerphi.am \\ Received August 19, 2011; revised October 22, 2011; accepted November 14, 2011
}

\begin{abstract}
The influence of hydrochloric or sulphuric acid treatment on the electro-physical properties of super-thin basalt fiber (STBF) made from Armenian basalt rocks was studied. Specific electric resistance for direct $\rho_{d c}$ and alternating $\rho_{a c}$ currents, dielectric parameters of $\varepsilon^{\prime}$ and $\varepsilon^{\prime \prime}$ were measured. It is shown that specific resistance and dielectric parameters of super-thin basalt fiber change essentially after hydrochloric or sulphuric acid treatment. The temperature dependences of these parameters were studied, too, and their non-monotonic behavior was observed. The probable variation of mentioned STBF parameters is explained by different water absorption capacity of pores as a result of acid treatment.
\end{abstract}

Keywords: Super-Thin Basalt Fiber, Water Molecule, Hydrochloric and Sulphuric Acid Treatment, Dipole-Relaxation

\section{Introduction}

Natural basalt rock is a porous aluminum-silicate hard material having volcanic origin. The processed basalt samples are used in industry: for construction, water drainage, insulation and so on [1-3]. After it was made possible to produce continuous basalt fibers from rock [4-6], their application was expanded as heat- and sound-insulators [7-9]. Besides, due to their high thermal stability, ecological compatibility and inertness with relation to the majority of aggressive materials, basalt fibers are used for filtering of industrial gas emissions without preliminary cooling [10].

STBF with diameter of a few microns are 1D crystals and possess all features of nanocrystalline materials (1D crystal, quantum dimensional effect) being of scientific and practical interest. Hence, these materials are interesting from the point of view of their electro-physical properties too and it is necessary for more systematic study of mentioned parameters, as well as their dependence on various external factors such as temperature, humidity, chemical modification, etc. Such works are scarce in scientific literature and available papers only present research on basalt rocks [11].

This paper for the first time presents electro-physical and thermal characteristics of super-thin basalt fibers (STBF) prepared from Armenian basalt rocks with average diameter of less than $10 \mu \mathrm{m}$ after treatment by hydrochloric or sulphuric acid.

\section{Experimental Materials and Procedures}

The samples of STBFs were prepared using standard technology [4-6] on Armenian basalt rocks (near Abovyan city). For technical applications STBFs are manufactured in the form of layered wool with packing bulk density $D=0.25 \mathrm{~g} / \mathrm{cm}^{3}$ that is considerably lower than the real fiber density $\left(D_{R}=2.7-2.8 \mathrm{~g} / \mathrm{cm}^{3}\right)[4,5,12]$. For measurements, pieces of the wool were cut into flat rectangular felt having an area from $0.7 \mathrm{~cm}^{2}$ to $1.5 \mathrm{~cm}^{2}$. Then these samples were placed between two copperplated laminated bakelite slabs. The same slabs were 
used as electric probes, to which ac or dc fields were applied. Probes with the samples were attached on a plastic holder, specific resistance of which $\left(>10^{17} \Omega \cdot \mathrm{cm}\right)$ was higher than that of the measured materials.

As a result of acid treatment of STBFs their structural and, hence, many physical properties may change. The samples were dried to constant weight during 8 hours at temperatures $115^{\circ} \mathrm{C}-120^{\circ} \mathrm{C}$. Initial sample after leaching and drying loses $51.5 \%$ of its weight. According to the results of chemical analysis, the end-product has the following structure: $\mathrm{SiO}_{2}-95.56 \%, \mathrm{Al}_{2} \mathrm{O}_{3}-2.25 \%, \mathrm{Fe}_{2} \mathrm{O}_{3}-$ $0.8 \%$ (amounting to $98.61 \%$ ).

Chemically modified samples in hydrochloric or sulphuric acid are referred as samples 1 and 2, correspondingly. For these samples, specific electric resistance for direct $\rho_{d c}$ and alternating $\rho_{a c}$ current and then, dielectric parameters $\varepsilon^{\prime}$ and $\varepsilon^{\prime \prime}$ were measured. The specified parameters were measured at the temperature from $100 \mathrm{~K}$ to $365 \mathrm{~K}$ and relative humidity of air not more than $50 \%$. Parameters $\varepsilon^{\prime}, \varepsilon^{\prime \prime}$ and $\rho_{a c}$ for basalt fibers were measured by means of a precise bridge for measurement of capacities (TESLA BM $400 \mathrm{G}$ ). This bridge enables to measure loss tangent $\tan \delta$ to 0.1 and capacity accurate to $\pm 1 \%$ at a fixed frequency of $800 \mathrm{~Hz}$. To measure higher $\varepsilon^{\prime \prime}$, another transformer bridge circuit was developed to measure $\tan \delta$ to 50 at frequencies from $200 \mathrm{~Hz}$ to $1 \mathrm{MHz}$. Using this device, it is possible to measure active and reactive components of signals from the investigated samples with accuracy up to $\Delta G=10^{-8} \Omega^{-1}$ and $\Delta C=0.05 \mathrm{pF}$, correspondingly. Calibration of the device and accuracy testing of the measured objects were carried out for known values $\mathrm{R}$ and $\mathrm{C}$, which were previously measured using impedance meter BM 507 and capacity meter BM $400 \mathrm{G}$, correspondingly.

The value of $\varepsilon^{\prime}$ was determined from expression $\varepsilon^{\prime}=C / C_{0}$, where $C$ is the capacity of a flat capacitor with dielectric and $C_{0}$ capacity of this capacitor without dielectric. Parameter $\varepsilon^{\prime \prime}$ was calculated from formula $\varepsilon^{\prime \prime}=\varepsilon^{\prime} \tan \delta$ and $\rho_{a c}$ was determined by formula $\rho_{a c}=\left(\varepsilon_{0} \varepsilon^{\prime \prime} \omega\right)^{-1}$, where $\varepsilon_{0}$ is dielectric constant, $\omega=2 \pi f$ is angular frequency of the electric field [13, 14]. Specific resistance of the sample for direct current $\rho_{d c}$ was determined by dual probe method using formula $\rho_{d c}=U S / I d$, where $U$ is a direct current voltage applied to the sample, $I$ is a current passed through it, $S$ is an effective area of the sample, and $d$ is an effective thickness of the sample in the current direction. For our samples $d \leq 1 \mathrm{~mm}$. Resistance measurements ( $R=U / I)$ of the sample for direct current were carried out using electrometric voltmeter V7-30 which allows measurements of $R$ up to $10^{18} \Omega$.

The weight of investigated samples varied in the range from 25 to $40 \mathrm{mg}$. Relative error in all types of the ful- filled measurements did not exceed 5\%.

\section{Experimental Results and Discussion}

The results of the effect of hydrochloric $(\mathrm{HCl})$ or sulphuric acid $\left(\mathrm{H}_{2} \mathrm{SO}_{4}\right)$ processing on the electro-physical properties of super-thin basalt fiber (STBF) are presented in Figures 1-6. It is seen from Figure 1 that $\varepsilon^{\prime}(T)$ and $\varepsilon^{\prime \prime}(T)$ curves reveal a maximum corresponding to minimum of $\rho_{a c}(T)$ for both samples. For the sample 2 minimum is shifted towards higher temperatures by 30 degrees (Figure 2). In this case specific electrical resistiv-

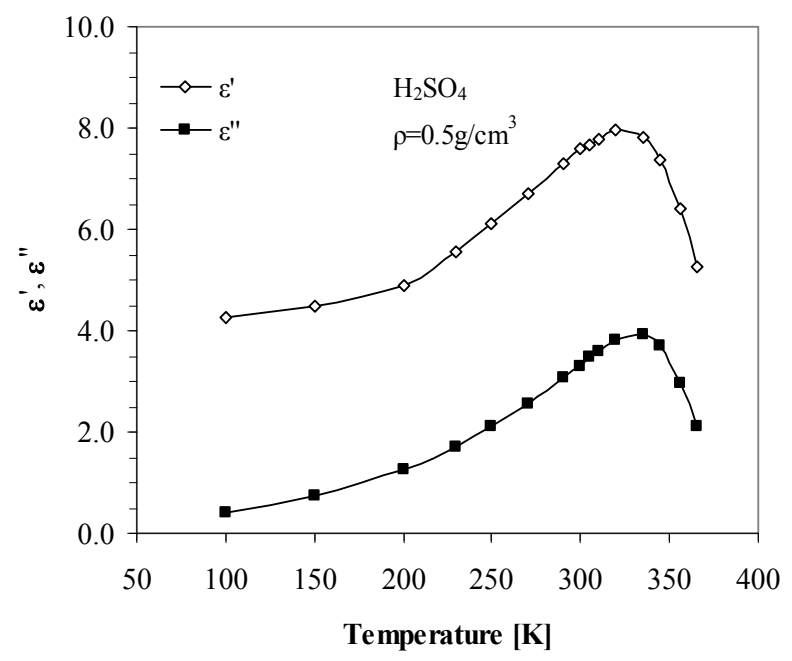

Figure 1. Temperature dependence of dielectric permeability $\varepsilon^{\prime}$ and dielectric loss $\varepsilon^{\prime \prime}$ coefficients (at frequency $1 \mathrm{kHz}$ ) for the chemically modified STBF samples by sulphuric acid.

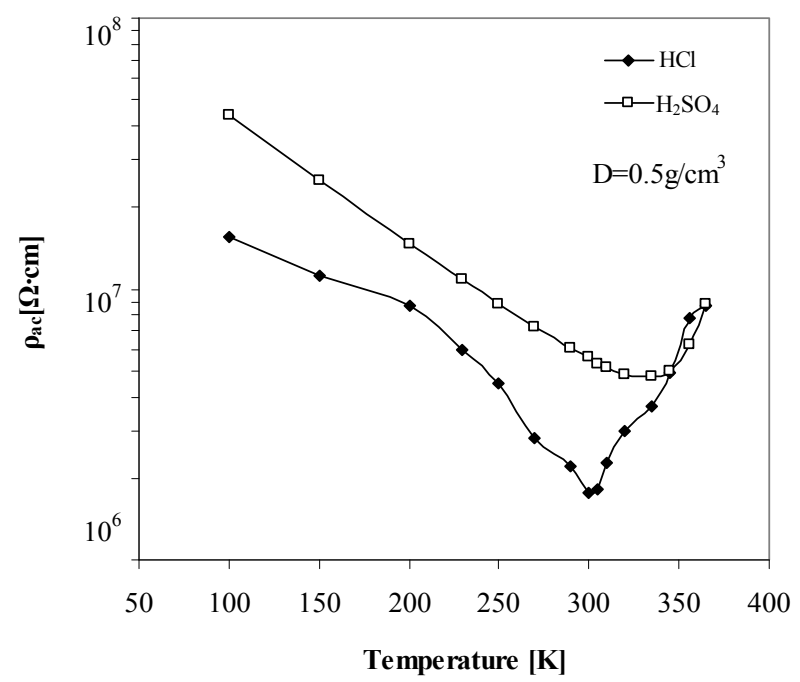

Figure 2. Temperature dependence of specific electrical resistivity $\rho_{a c}$ for the frequency of $1 \mathrm{kHz}$ of alternating current field for the chemically modified STBF samples by sulphuric and hydrochloric acids. 
ity $\rho_{a c}$ of the sample 2 at temperature $300 \mathrm{~K}$ is approximately 3 times higher than that for the sample 1 . At the same time this difference for $\rho_{\mathrm{dc}}$ varies from 3 to $4 \mathrm{de}-$ pending on the time passed after switching on of dc electric field (Figure 2). The presence of maxima on $\varepsilon^{\prime}(T)$ and $\varepsilon^{\prime \prime}(T)$ curves (see Figure 3) or minima on $\rho_{a c}(T)$ curves for both samples (Figure 2) means that depending on temperature at least two competing mechanisms could act. It is confirmed by the presence of two strongly distinguishing slopes in temperature intervals from $100 \mathrm{~K}$ to $200 \mathrm{~K}$ and from $200 \mathrm{~K}$ to $300 \mathrm{~K}$ on both $\varepsilon^{\prime}(T)$ and $\varepsilon^{\prime \prime}(T)$ curves (Figure 1), and $\rho_{a c}(T)$ curves (Figure 4). The slopes presented in the figures are apparently related to the presence of weakly connected and strongly connected

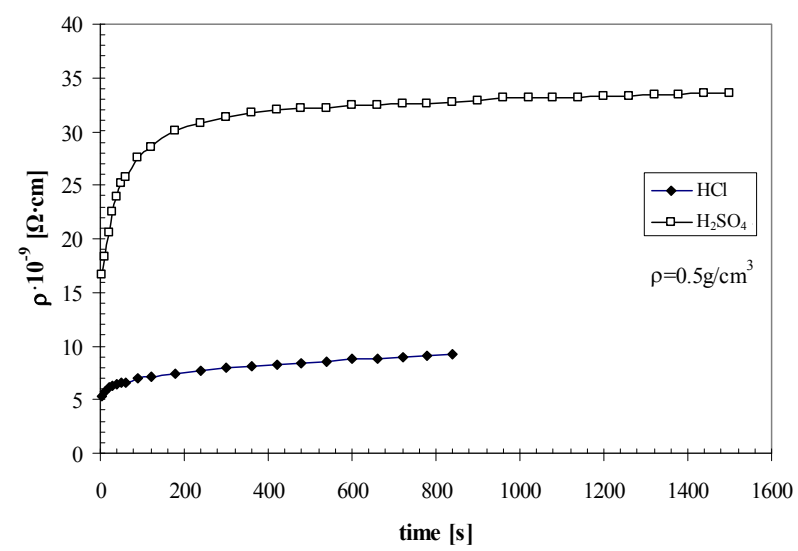

Figure 3. Dependence of specific electrical resistivity for field of samples 1 and 2 on duration of the applied direct current field $\left(T_{\text {meas }}=20.4^{\circ} \mathrm{C}\right.$, relative air humidity of $49.9 \%$, the packing density of the sample here is the same as in Figures 1, 2 and 4: $D=0.5 \mathrm{~g} / \mathrm{cm}^{3}$ ).

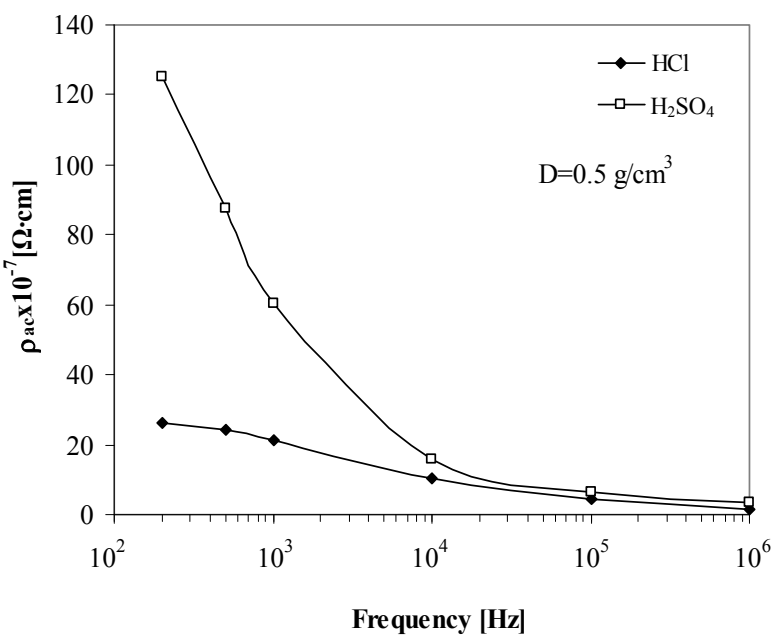

Figure 4. Frequency dependence of specific electric conductivity for alternating current $\left(\rho_{a c}\right)$ at $T=30^{\circ} \mathrm{C}$ for the chemically modified STBF samples by leaching using sulphuric and hydrochloric acids. dipole water molecules. Decreasing character of $\rho_{a c}$ on frequency of the applied field (see Figure 4) shows that in both samples the mechanism of dipole polarization $[13,14]$ takes place. According to [12], starting from $40^{\circ} \mathrm{C}$ super-thin basalt fibers reveal a remarkable water loss that causes sharp decrease of $\varepsilon^{\prime}$ and $\varepsilon^{\prime \prime}$ or increase of $\rho_{a c}$ and occurrence of maxima and minima on temperature dependences of electric characteristics (Figures 1 and 2). On the other hand, it is shown in [12] that the samples after processing in sulphuric acid reveal higher adsorbing ability for water vapor. Besides, the fraction of strong bounded water molecules is higher in this sample. This means that water begins considerably evaporate at higher temperature thus causing the mentioned shift for the sample 2 with corresponding extreme values of 30 degrees towards higher temperatures in comparison with the sample 1.

In favour of higher water content testifies the fact that for the sample 2 the $\rho_{a c}$ decreases faster depending on frequency of alternating electric field, than for the sample 1 (Figure 4). This fact correlates with results of dependence of $\rho_{d c}$ on duration of the action of direct electric field for both samples (Figure 3). It is seen that at reduction of the action of direct electric field (which is equivalent to application of high frequencies of alternating electric field) the $\rho_{d c}$ values for both kinds of leached (hydrochloric and sulphuric acids) samples become nearer.

The results of the influence of packing density on the electro-physical properties of STBF samples are presented in Figures 5-6. It is seen from Figure 5 that for the chemically modified STBF samples using sulphuric acid the parameter $\rho_{a c}$ decreases gradually with increasing of packing density. This decrease is by factor of 3 when the packing density increases from $0.5 \mathrm{~g} / \mathrm{cm}^{3}$ to 1 $\mathrm{g} / \mathrm{cm}^{3}$. While for the sample modified using hydrochloric acid the parameter $\rho_{a c}$ decreases by factor 3.6 at the same conditions (see in Figure 5). However the results of investigations with direct current field application showed that the curves of $\rho_{d c}$ depending of packing density have non monotonous character and the observed changes for sample 2 is 2 times while for sample 1 it is almost 14 (Figure 6). Note that non monotonous dependence of filtering ability of the nanofiber system on packing density was observed in recent publication [15]. The reason of the reduction of $\rho_{a c}$ and $\rho_{d c}$ for both samples may be in increasing of mechanical hardness after their chemical treatments which may increase the packing density of fibers and hence, a reduction of the distance between them causing easy the charge transfer between fibers and, in result, decreasing of $\rho_{a c}$ and $\rho_{d c}$.

The above mentioned results allow assuming that after treatment of STBF by sulphuric acid these samples be- 

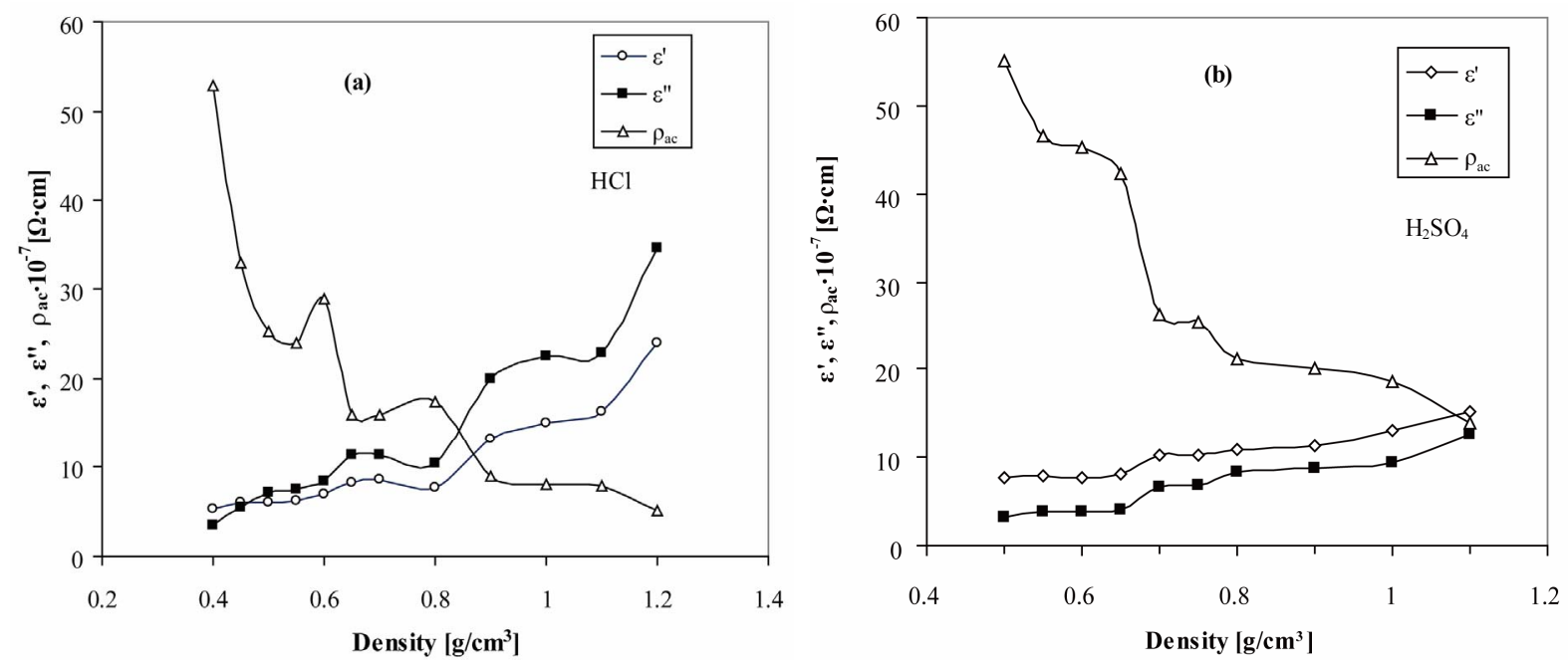

Figure 5. Dielectric permeability $\varepsilon^{\prime}$ and dielectric loss $\varepsilon^{\prime \prime}$ coefficients (at frequency $1 \mathrm{kHz}$ ) depending on packing density for the chemically modified STBF samples using sulphuric acid.

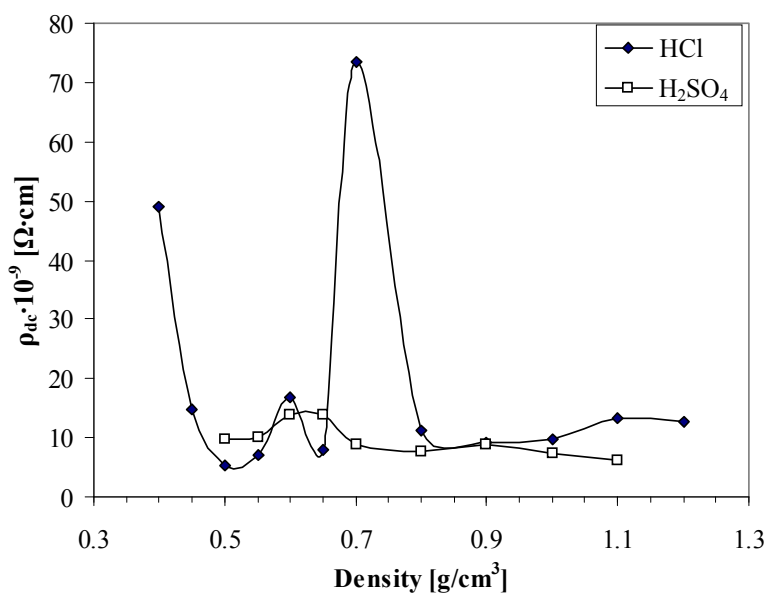

Figure 6. Specific electrical resistivity $\rho_{d c}$ for direct electric field depending on packing density for the STBF samples chemically modified using hydrochloric (a) and sulphuric (b) acids. The measurements were carried out after 5 second switch on the d-c electric field.

come more stable to the external influences. In particular it is expressed in low sensitivity of their electro- physical parameters to the temperature change, packing density and rapid achieving of final value of $\rho_{d c}$ after switch on direct field (see Figures 2, 3, 5 and 6). Note that this time is about $200 \mathrm{~s}$ for the sample 2 while for the sample 1 this time is significantly higher.

\section{Conclusions}

Thus the main results on research of the influence of acid treatments on the electro- physical parameters of STBF should be concluded as follows:

1) Electro-physical parameters of samples after sul- phuric and hydrochloric leaching depending on temperature show a peak (or minimum). The appearance of the peak (or minimum) is conditioned by variation of dipole mechanism of polarization, caused by thermal activation of water molecules and further escape from the sample. And its strong temperature quenching is conditioned by high capability of absorbed water.

2) The results showed that specific electrical resistance on alternating current in STBFs, leached both in sulphuric and hydrochloric acids, depending on their packing density, qualitatively shows similar behaviour: it decreases stepwise, but in first case this decrease is quite weak. However, the sensitivity of specific electrical resistance on direct current, compared to variation of packing density is a few times more in sample, treated with hydrochloric acid.

\section{Acknowledgements}

This work was supported by International Science and Technology Center (ISTC) Project No. A-1605. The authors are grateful for this assistance.

\section{References}

[1] http://naftaros.ru/articles/3/ Basalt Fibers and Products

[2] http://naftaros.ru/articles/21 Basalt Fibers/

[3] E. B. Kondratyuk and L. F. Komarova, "Change of Stability of the Silicate Fibers at the Process of Composite Materials Production," Polzunovsky Vestnik, Barnaul, 2008, pp. 212-217.

[4] http://www.junantai.com/en/products/basalt/basalt_fiber. htm, Basalt Fiber Products

[5] http://www.bvolokno.ru/index.php Basalt Fiber 
[6] http://naftaros.ru/kompozitsionnye /bazaltovye tehno/os novnye_harakte/ Basic properties and advantages of basalt fibers.

[7] http://www.izhstroy.ru/catalog/articles/9/Heater from the Super-thin Basalt Fiber

[8] A. A. Litus, I. N. Sinitsyn, S. E. Artemenko and A. A. Zemljansky, "Noise-Attenuating and Sound-Proof Materials on the Basis of Basalt Fibers," Plasticheskiye Massy, N1, 2008, pp. 25-27.

[9] C. E. Artemenko, S. V. Arzamastsev and D. A. Shatunov, "Basalt Fiber as an Effective Reinforcing Material for Road Building," Plasticheskiye Massy, N1, 2008, pp. 1-6.

[10] S. E. Artemenko, I. N. Sinitsyn, N. A. Ustinov and A. P. Seredishkin, "Research of Hydromechanical Characteristics of Basalt Filter Elements," Plasticheskiye Massy, N1, 2008, pp. 21-25.

[11] M. S. Mostafa, N. Afify, A. Gaber and E. F. Abozid, Electrical Resistivity of Some Basalt and Granite Samples from Egypt," Physics, Vol. 26, No. 1, 2003, pp.
25-32.

[12] I. N. Bekman, "Diagnostics of Basalt Fiber Adsorbents, Vestnik MGU, Series 2," Chemistry, Vol. 44, No. 5, 2003, pp. 342-351.

[13] V. V. Pasynkov and V. S. Sorokin, "Materials for Electronic Technique Mosc," in Russian, Vyschaya shkola" 1986, p. 368.

[14] M. E. Borisova and S. N. Kojkov, "Physics of Dielectrics," in Russian, Publishing Office of Leningrad University, Leningrad, 1979, p. 240.

[15] J. Wang, S. C. Kim and D. Y. H. Pui, "Investigation of the Figure of Merit for Filters with a Single Nanofiber Layer on a Substrate," Journal of Aerosol Science, Vol. 39, No. 4, 2008, pp. 323-334. doi:10.1016/j.jaerosci.2007.12.003

[16] D. E. Zimin and O. S. Tatarintceva, Change of Stability of the Silicate Fibers at the Process of Composite Materials Production," Polzunovsky Vestnik, N3, 2008, pp. 217-219. 